Check for updates

Cite this: RSC Adv., 2019, 9, 9718

Received 3rd December 2018

Accepted 22nd January 2019

DOI: $10.1039 / c 8 r a 09932 d$

rsc.li/rsc-advances

\section{The effect of $\mathrm{ZnCl}_{2}$ activation on microwave absorbing performance in walnut shell-derived nano-porous carbon}

\author{
Lixi Wang, (D)*ab Panpan Zhou, ${ }^{\text {ab }}$ Yu Guo, e Jing Zhang, ${ }^{\text {cd }}$ Xu Quu, ${ }^{\text {ab }}$ Yongkang Guan, ${ }^{\text {ab }}$ \\ Mingxun $\mathrm{Yu}^{\mathrm{e}}{ }^{\mathrm{H}}$ Hongli Zhu ${ }^{\mathrm{e}}$ and Qitu Zhang ${ }^{\mathrm{ab}}$
}

Porous carbon has been expected to be a potential candidate as a lightweight and efficient microwave absorber. Nano-porous carbon carbonized directly from a walnut shell exhibits narrow microwave absorption frequency bandwidth, while the activation process can adjust the pore structure and optimize the microwave absorption performance. Herein, porous carbon materials were successfully prepared using walnut shells as precursors and $\mathrm{ZnCl}_{2}$ as the activating agent. The superior microwave absorption performances of the as-prepared samples could be attributed to the well-developed pore structures and the enhanced dielectric loss capacities of the samples. The interfacial polarization in the walls of the pores and the defects in the samples significantly contributed to the enhancement of the dielectric loss capacities of the samples. In this work, the broadband microwave absorbing porous carbon exhibited an effective absorption bandwidth (reflection loss $\leq-10 \mathrm{~dB}$ ) of $7.2 \mathrm{GHz}$ (ranging from $10.8 \mathrm{GHz}$ to 18.0 $\mathrm{GHz}$ ) when the absorber thickness was $2.5 \mathrm{~mm}$. In addition, an effective absorption bandwidth of 6.0 $\mathrm{GHz}$ (ranging from $11.4 \mathrm{GHz}$ to $17.4 \mathrm{GHz}$ ) could also be achieved when the absorber thickness was only $2.0 \mathrm{~mm}$. The samples exhibited low densities, strong microwave absorption performances and wide effective absorption bandwidths with thin absorber thicknesses, due to which they have a great potential as lightweight and efficient microwave absorbers.

\section{Introduction}

Nowadays, with the rapid development of electromagnetic techniques, electromagnetic radiation and electromagnetic interference have disturbed people's daily life. Electromagnetic wave pollution may not only hamper the effectiveness of sophisticated electronic instruments but also damage the ecological environment and threaten human health. ${ }^{1-3}$ To address this growing problem, the exploitation of efficient microwave absorption materials that can convert the electromagnetic energy to other forms of energy is considered the most effective solution. In view of practical applications, microwave absorption materials should not only have strong microwave absorption but also have excellent properties such as a broad absorption frequency bandwidth, thin coating thickness, light weight, and good thermal stability. ${ }^{4-6}$

\footnotetext{
${ }^{a}$ College of Materials Science and Engineering, Nanjing Tech University, Nanjing 210009, China.E-mail: wanglixi_njut@163.com; wanglixi@njtech.edu.cn

biangsu Collaborative Innovation Center for Advanced Inorganic Function Composites, Nanjing 210009, China

${ }^{c}$ Nanjing Center, China Geological Survey, Nanjing 210016, China

${ }^{d}$ Supervision and Testing Center of East China, Mineral Resources of the Ministry of Land and Resources, Nanjing 210016, China

${ }^{e}$ Institute 53 of China's Ordnance Industry, Jinan 250031, China
}

According to the electromagnetic loss mechanism, microwave absorption materials are generally divided into magnetic loss materials and dielectric loss materials. Traditional magnetic loss materials include ferrites, ${ }^{7-9}$ magnetic metals ${ }^{10}$ and alloys, ${ }^{11}$ and they are favourable for absorbing microwaves because of considerable magnetic loss. Although these magnetic materials can have strong microwave absorption, they have large densities, which limit their practical applications. Dielectric loss materials include conductive polymers, ${ }^{\mathbf{1 2}}$ semiconductor-based materials, ${ }^{13}$ ceramics, ${ }^{\mathbf{1 4}}$ and carbon materials. ${ }^{15}$ Among them, carbonaceous microwave absorbers have aroused intensive attention because of their excellent physical and chemical performances such as low density, superior electric properties, good mechanical strength, thermal stability and corrosion resistance. ${ }^{16-18}$ In particular, porous carbons have large specific surface areas and can attenuate microwaves effectively by good dielectric loss, multiple reflections and scattering of microwaves. ${ }^{19-21}$ At present, challenges remain in the field of microwave absorption since the effective absorption frequency bandwidth of most microwave absorbers is still unsatisfactory and the preparation technology is still complicated. It is necessary to exploit easily prepared and lowcost microwave absorbers that have strong microwave absorption and broad effective absorption frequency bandwidth and are light in weight. 
Recently, biological materials are receiving wide attention. They have been used in various fields and they can be used in super capacitor electrodes, ${ }^{22-24}$ battery anodes, ${ }^{25}$ carbon dioxide capture, ${ }^{26}$ organic pollutant adsorption materials, ${ }^{27}$ etc. In consideration of the rich naturally porous structures in biomass materials, some researchers have tried to use them as candidates of microwave absorbers through carbonization. ${ }^{\mathbf{2 1 , 2 8 , 2 9}}$ However, natural pores in most biomass materials are very large and they may not be sensitive to microwaves. Hence, pores with a suitable size in the interior of biomass materials are favourable for increasing the multiple reflections and scattering of microwaves. A simple approach is to make use of highly acidic or strong alkaline substances to etch biomass materials during carbonization. These corrosive substances include $\mathrm{KOH}^{\mathbf{3 0 , 3 1}}$ and $\mathrm{H}_{3} \mathrm{PO}_{4} \cdot{ }^{32,33}$ Different corrosive substances can form different pore structures in biomass materials. Usually, biomass materials etched by strong alkaline substances can have numerous micropores and high specific surface areas. ${ }^{34}$ Nevertheless, strong alkaline substances will destroy the natural large pores of biomass materials and make microwaves difficult to spread into the interior of the material. The ideal pore structures for efficient microwave absorbing are hierarchical porous structures. Microwaves radiate into the interior of the material through the large pores on the outer surface of the material first and then make multiple reflections on the small pore walls inside the material. Therefore, it is important to retain the natural large pores of biomass materials.

Herein, walnut shells were used as the carbon source to prepare porous carbon because walnut shells have many natural large pores that help microwaves to propagate into the interior of the material easily. In order to improve the microwave absorption performance of the material, it is necessary to create small pores in the interior of the material to enhance interfacial polarization relaxation loss and make microwaves reflect and scatter in the small pore structure. Zinc chloride in an aqueous solution is faintly acidic, and it will not destroy the natural large pores on the outer surface of the walnut shells, which is observed with highly acidic or strong alkaline substances such as $\mathrm{H}_{3} \mathrm{PO}_{4}$ or $\mathrm{KOH}$. In addition, the zinc chloride aqueous solution can flow into the interior of the walnut shells to etch lignin and cellulose with threedimensional network structures to create three-dimensional interconnected small pores. Thus, zinc chloride was used to corrode walnut shells. In this work, walnut shells were first carbonized at $400{ }^{\circ} \mathrm{C}$ and then immersed in the zinc chloride aqueous solution with different concentrations and calcined at various temperatures; the porous carbon was finally obtained after washing and drying (Fig. 1). The optimized porous carbon exhibited good dielectric loss capacities and excellent microwave absorption performance; the effect of $\mathrm{ZnCl}_{2}$ activation on the microwave absorbing performance in the walnut shell-derived nano-porous carbon was also discussed in detail in this work.

\section{Experimental}

\subsection{Raw materials}

Huang long walnut shells were bought at Henan Yuan Run Water Treatment Material Co., Ltd and were crushed into

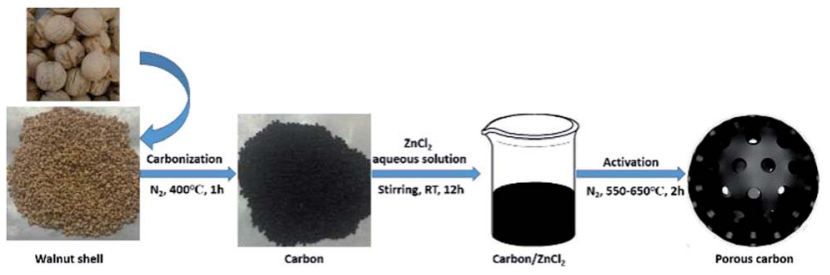

Fig. 1 Schematic illustration of the preparation of walnut shell-derived nano-porous carbon through $\mathrm{ZnCl}_{2}$ activation.

particles in the size range of $0.8-1.6 \mathrm{~mm}$. High purity nitrogen (>99.999\%) was bought at Nanjing Sanle Electronic Information Industry Group Co., Ltd. Zinc chloride $\left(\mathrm{ZnCl}_{2}\right)$ was purchased from Shanghai Xinbao Industry of Fine Chemical. Absolute ethyl alcohol was purchased from Wuxi City Yasheng Chemical Co., Ltd. All of the chemical reagents were analytically pure and used without further purification.

\subsection{Preparation of samples}

In this work, walnut shell-derived nano-porous carbon was prepared by $\mathrm{ZnCl}_{2}$ activation, as shown in Fig. 1. The details of the experiment are as follows: first, walnut shells (size: 0.8-1.6 $\mathrm{mm}$ ) were washed thoroughly with absolute ethyl alcohol and deionized water several times and then dried at $60{ }^{\circ} \mathrm{C}$. The dried walnut shells underwent a pyrolysis process under nitrogen atmosphere in a tube furnace (from room temperature to $400{ }^{\circ} \mathrm{C}, 5{ }^{\circ} \mathrm{C} \mathrm{min}^{-1} ; 400{ }^{\circ} \mathrm{C}, 1 \mathrm{~h}$; from $400{ }^{\circ} \mathrm{C}$ to room temperature, cooled in the furnace) and the carbonized products and some tar were formed. A certain amount of zinc chloride $(12 \mathrm{~g}$, $18 \mathrm{~g}, 24 \mathrm{~g}$ and $30 \mathrm{~g}$ ) was added into $30 \mathrm{~mL}$ deionized water and stirred to form the homogeneous $\mathrm{ZnCl}_{2}$ aqueous solution with different concentrations. Also, $6 \mathrm{~g}$ of as-prepared carbonized products was then immersed into the zinc chloride aqueous solution and stirred for $12 \mathrm{~h}$ at room temperature. After being dried at $60{ }^{\circ} \mathrm{C}$, the mixture was heated up to the specified temperatures $\left(550{ }^{\circ} \mathrm{C}, 600{ }^{\circ} \mathrm{C}\right.$ and $\left.650{ }^{\circ} \mathrm{C}\right)$ at a heating rate of $5{ }^{\circ} \mathrm{C} \min ^{-1}$, held for $2 \mathrm{~h}$ under nitrogen atmosphere and then cooled in the furnace. After thermal treatment, the as-prepared samples were washed with absolute ethyl alcohol and hot deionized water several times and then dried at $60{ }^{\circ} \mathrm{C}$. The resulting porous biomass carbon materials are marked as PC- $X$ $Y$, where $X$ represents the $\mathrm{ZnCl}_{2}$ content $(12 \mathrm{~g}, 18 \mathrm{~g}, 24 \mathrm{~g}$ and 30 $\mathrm{g}$ ) in the $\mathrm{ZnCl}_{2}$ aqueous solution and $Y$ represents the calcination temperature $\left(550{ }^{\circ} \mathrm{C}, 600{ }^{\circ} \mathrm{C}\right.$ and $\left.650{ }^{\circ} \mathrm{C}\right)$. For example, PC18-600 represents that the $\mathrm{ZnCl}_{2}$ content in the $\mathrm{ZnCl}_{2}$ aqueous solution is $18 \mathrm{~g}$ and the calcination temperature is $600{ }^{\circ} \mathrm{C}$. For comparison, walnut shells were also treated with the same process as that for PC-18-600 without using $\mathrm{ZnCl}_{2}$, and the product was marked as C-600.

\subsection{Characterization of samples}

The morphologies of the samples were observed by transmission electron microscopy (FEI G2F20, FEI, USA). The Raman spectra of the samples were recorded using a Raman spectrometer (Labram HR800, Horiba, Japan, $514 \mathrm{~nm}$ laser) to 
analyze the graphitization degree and the defective nature of the samples. X-ray photoelectron spectroscopy (Escalab 250Xi, Thermo, USA) was performed to analyze the surface chemical state of the sample. Pore structures of the samples were characterized by nitrogen adsorption-desorption isotherms at $77 \mathrm{~K}$ on a Belsorp-Max surface area analyzer (Belsorp-Max, MicrotracBEL, Japan). All samples were degassed at $150{ }^{\circ} \mathrm{C}$ under vacuum for $12 \mathrm{~h}$ before the measurements. The BrunauerEmmett-Teller (BET) equation and the Horvath-Kawazoe (HK) theory were used to calculate the specific surface area and the pore size distribution of the sample, respectively. Total pore volume was calculated at a relative pressure $P / P_{0}=0.991$.

\subsection{Microwave absorption measurements}

Paraffin wax was used as the binder, and the as-prepared samples and molten paraffin wax with a weight ratio of $7: 3$ were mixed uniformly and then pressed into toroidal-shaped samples $\left(\varphi_{\text {out }}=7.00 \mathrm{~mm}, \varphi_{\text {in }}=3.04 \mathrm{~mm}\right)$. The relative complex permittivity $\left(\varepsilon_{\mathrm{r}}=\varepsilon^{\prime}-j \varepsilon^{\prime \prime}\right)$ and the relative complex permeability $\left(\mu_{\mathrm{r}}=\mu^{\prime}-j \mu^{\prime \prime}\right)$ of the toroidal-shaped samples in the frequency range of $2-18 \mathrm{GHz}$ can be obtained by using the coaxial-line method on an Agilent 85050D vector network analyzer. Finally, the reflection loss (RL) values can be obtained according to the transmission line theory using the following equations: ${ }^{35-37}$

$$
\begin{gathered}
Z_{\text {in }}=\left(\mu_{\mathrm{r}} / \varepsilon_{\mathrm{r}}\right)^{1 / 2} \tanh \left[j(2 \pi f d / c)\left(\mu_{\mathrm{r}} \varepsilon_{\mathrm{r}}\right)^{1 / 2}\right] \\
\mathrm{RL}=20 \log \left|\left(Z_{\text {in }}-1\right) /\left(Z_{\text {in }}+1\right)\right|
\end{gathered}
$$

Here, $Z_{\text {in }}$ is the normalized input characteristic impedance of the absorber, $\mu_{\mathrm{r}}$ and $\varepsilon_{\mathrm{r}}$ are the relative complex permeability and permittivity of the absorber, respectively, $f$ is the electromagnetic wave frequency, $d$ is the thickness of the absorber, and $c$ is the velocity of electromagnetic waves in free space $\left(3.0 \times 10^{8}\right.$ $\left.\mathrm{ms}^{-1}\right)$.

\section{Results and discussion}

\subsection{Morphologies and microstructures}

Fig. 2 exhibits the XRD patterns of the samples PC-18-550, C600, PC-18-600, PC-24-600, PC-30-600 and PC-18-650. We can see that all samples show similar peak shapes. Two broad and weak diffraction peaks located at 22.1 and 43.1 are assigned to the (002) and (100) crystal planes of graphitic carbon, respectively. ${ }^{37}$ The two weak peaks indicate a low graphitization degree and amorphous features of the porous carbon, agreeing with the TEM images.

To observe the detailed microstructures of the as-prepared sample, SEM and TEM images of the sample were examined, as shown in Fig. 3. Fig. 3(a) exhibits an SEM image of the carbonized sample particles. It shows that the carbon particles are irregular cubes with a size of $\sim 20 \mu \mathrm{m}$. In the highmagnification SEM photograph of PC-18-600 (Fig. 3(b)), we can see that there are some large pores in the surface of the sample with a size of $\sim 5 \mu \mathrm{m}$. From the TEM images, many small dark areas having lattice fringes can be clearly seen, indicating

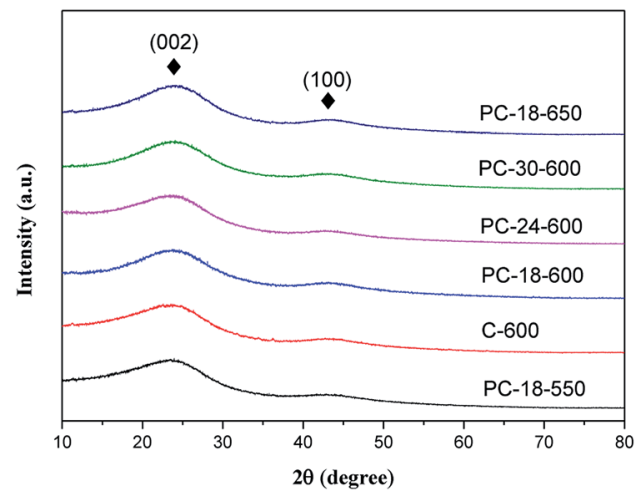

Fig. 2 XRD patterns of the samples.

the formation of many short-range ordered crystalline regions. The lattice spacing is $0.20 \mathrm{~nm}$ (Fig. 3(f)), corresponding to the (101) plane of graphite, which has been demonstrated by the literature named "Low temperature carbonization of cellulose nanocrystals for high performance carbon anode of sodium-ion batteries". ${ }^{38}$ However, numerous micropores destroyed the graphite structure, making the graphite lattice highly defective and twisty. These defects in the graphite lattice are conducive to microwave absorption because the defects in the crystal lattice can become polarization centers in the presence of microwaves, enhancing the dielectric loss capacity of the material; ${ }^{\mathbf{3 9}, 40}$ the
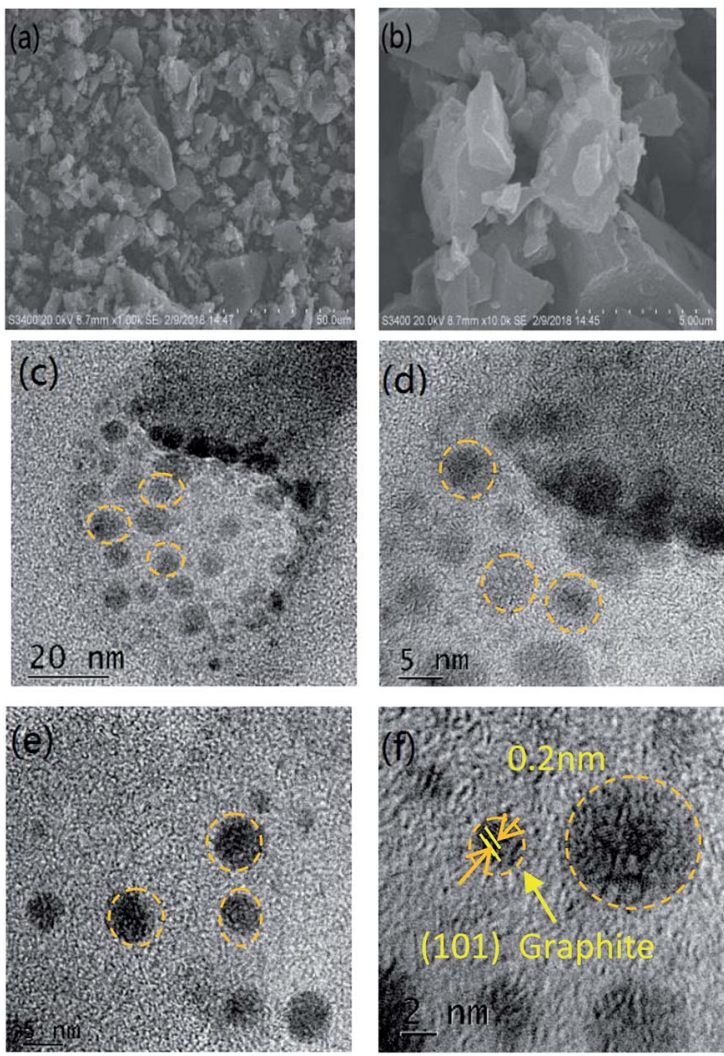

Fig. 3 SEM ( $a$ and $b$ ) and high-resolution TEM (c- $f$ ) images of PC-18600 at different magnifications. 
defects can also make the microwaves scatter around, which disperses the microwave energy.

To further analyse the characteristics of the pore structures of the as-prepared samples, $\mathrm{N}_{2}$ adsorption-desorption isotherm measurements were obtained, as shown in Fig. 4. Moreover, $S_{\mathrm{BET}}$ was calculated by the multiple point BET method; total pore volume was calculated at a relative pressure $P / P_{0}=0.991$ and $W_{\text {peak }}$ was estimated according to the Horvath-Kawazoe (HK) theory. The detailed specific surface area, total pore volume and the most probable pore size of the as-prepared samples are listed in Table 1.

As depicted in Fig. 4, the $\mathrm{N}_{2}$ adsorption-desorption isotherms of the as-prepared samples present similar variation tendencies; the $\mathrm{N}_{2}$ adsorbing capacity increases rapidly at a very low relative pressure and then, the $\mathrm{N}_{2}$ adsorbing capacity stays nearly constant with the increase in relative pressure. At the $\mathrm{N}_{2}$ desorption stage, the desorption isotherm stays almost overlapped with the adsorption isotherm. These $\mathrm{N}_{2}$ adsorptiondesorption isotherms can be classified into I type isotherms according to IUPAC classification, indicating that the asprepared samples have many micropores. As shown in Table 1, the walnut shell-derived carbon without using $\mathrm{ZnCl}_{2}$ (C-600) has the specific surface area of $435.3 \mathrm{~m}^{2} \mathrm{~g}^{-1}$, and the specific surface area of the walnut shell-derived carbon activated by $\mathrm{ZnCl}_{2}$ increases distinctly. For PC-30-600, its specific surface area can reach $640.2 \mathrm{~m}^{2} \mathrm{~g}^{-1}$.

For carbonaceous materials, Raman spectra are widely used to characterize their graphitization degree and the defective nature. Generally, carbonaceous materials have two typical characteristic peaks (D band and $\mathrm{G}$ band); the $\mathrm{D}$ band is attributed to disordered or defective $\mathrm{sp}^{3}$-hybridized carbon atoms, while the $\mathrm{G}$ band corresponds to the in-plane bondstretching motion of the pairs of $\mathrm{sp}^{2}$-hybridized graphite carbon atoms. ${ }^{4-43}$ Thus, the integrated intensity ratio of the $\mathrm{D}$ band to the $\mathrm{G}$ band $\left(I_{\mathrm{D}} / I_{\mathrm{G}}\right)$ is usually used to estimate the graphitization degree and the defect concentration of carbonaceous materials. ${ }^{44,45}$ Fig. 5 shows the typical Raman spectra of the as-prepared samples.

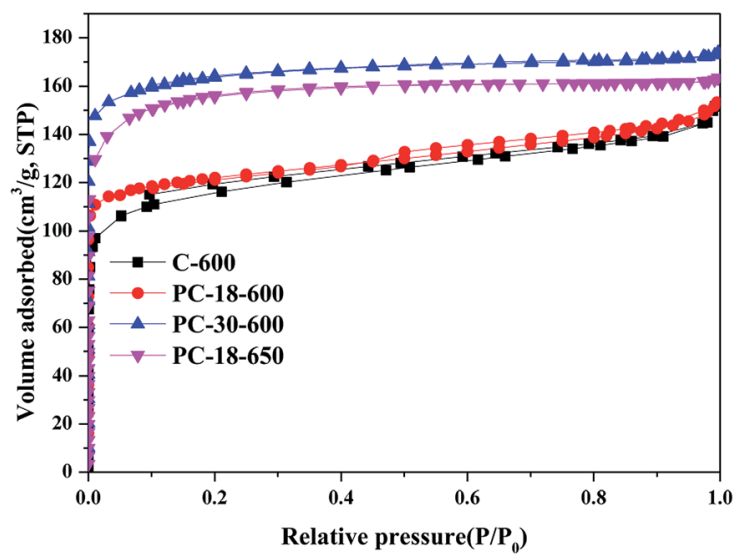

Fig. 4 Nitrogen adsorption-desorption isotherms of samples prepared at different conditions.
Table 1 Specific surface area $\left(S_{\mathrm{BET}}\right)$, total pore volume, and the most probable pore size $\left(W_{\text {peak }}\right)$ of samples prepared at different conditions

\begin{tabular}{llll}
\hline Sample & $S_{\text {BET }}\left(\mathrm{m}^{2} \mathrm{~g}^{-1}\right)$ & $\begin{array}{l}\text { Total pore volume } \\
\left(\mathrm{cm}^{3} \mathrm{~g}^{-1}\right)\end{array}$ & $W_{\text {peak }}(\mathrm{nm})$ \\
\hline C-600 & 435.3 & 0.2331 & 0.54 \\
PC-18-600 & 481.7 & 0.2346 & 0.54 \\
PC-30-600 & 640.2 & 0.2674 & 0.58 \\
PC-18-650 & 595.7 & 0.2515 & 0.56 \\
\hline
\end{tabular}

Among these samples, the D bands at around $1353 \mathrm{~cm}^{-1}$ and the $\mathrm{G}$ bands at around $1591 \mathrm{~cm}^{-1}$ can be clearly seen. The high $I_{\mathrm{D}} / I_{\mathrm{G}}$ values of the samples imply the distortion and many defects in the graphite structures, which indicate the low graphitization degree of the samples; this is in agreement with the TEM images (Fig. 3). Moreover, the calculated $I_{\mathrm{D}} / I_{\mathrm{G}}$ values of the samples decrease (from 1.45 to 1.32 ) with the increase in calcination temperature (from $550{ }^{\circ} \mathrm{C}$ to $650{ }^{\circ} \mathrm{C}$ ), which indicates the decrease in disordered or defective $\mathrm{sp}^{3}$-hybridized carbon domains in the samples with the increase in the calcination temperature.

The surface chemical state of the as-prepared PC-18-600 was characterized by X-ray photoelectron spectroscopy (XPS), as shown in Fig. 5. The general survey spectrum of PC-18-600 presents two typical peaks at about $284.8 \mathrm{eV}$ and $533.4 \mathrm{eV}$, corresponding to C1s and O1s (Fig. 6(a)). Based on the XPS analysis, the mole ratio of $\mathrm{C}$ and $\mathrm{O}$ was found to be $13: 1$. The high-resolution spectrum of C1s (Fig. 6(b)) can be decomposed into two peaks. The dominant peak at $284.8 \mathrm{eV}$ is assigned to the graphite carbon and the small peak at $286.1 \mathrm{eV}$ corresponds to $\mathrm{C}-\mathrm{O}{ }^{41,46}$ The high-resolution spectrum of O1s (Fig. 6(c)) can be resolved into two peaks located at $532.0 \mathrm{eV}$ and $533.5 \mathrm{eV}$, corresponding to $\mathrm{C}=\mathrm{O}$ and $\mathrm{C}-\mathrm{O}$ bonds. ${ }^{47}$

\subsection{Microwave absorption properties}

It is widely recognized that the microwave absorption performance of a material is associated with its relative complex permittivity $\left(\varepsilon_{\mathrm{r}}=\varepsilon^{\prime}-j \varepsilon^{\prime \prime}\right)$ and relative complex permeability $\left(\mu_{\mathrm{r}}=\mu^{\prime}-j \mu^{\prime \prime}\right)$. Accordingly, the real parts of relative complex

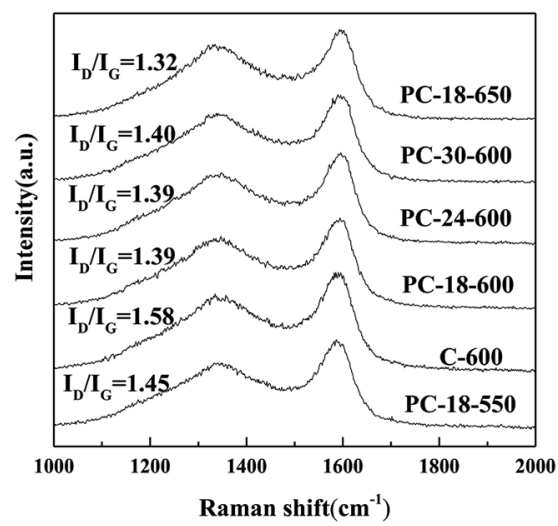

Fig. 5 Raman spectra of samples prepared at different conditions. 

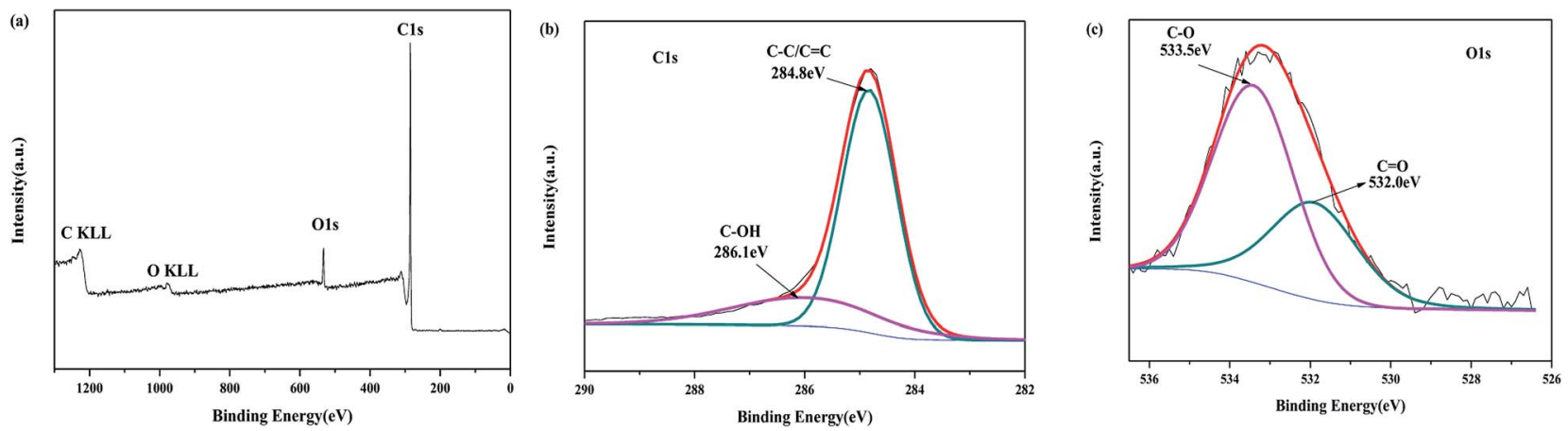

Fig. 6 XPS spectra of PC-18-600: (a) survey scan, (b) C1s and (c) O1s.

permittivity $\left(\varepsilon^{\prime}\right)$ and permeability $\left(\mu^{\prime}\right)$ reflect the storage capability of electromagnetic energy; the imaginary parts of relative complex permittivity $\left(\varepsilon^{\prime \prime}\right)$ and permeability $\left(\mu^{\prime \prime}\right)$ reflect the dissipation capability of electromagnetic energy. ${ }^{48}$ The dielectric loss tangent and the magnetic loss tangent can be obtained using the equations $\tan \delta_{\mathrm{E}}=\varepsilon^{\prime \prime} / \varepsilon^{\prime}$ and $\tan \delta_{\mathrm{M}}=\mu^{\prime \prime} / \mu^{\prime}$, respectively, which can quantify the energy loss versus the energy storage..$^{49}$ Hence, the electromagnetic parameters of the as-prepared absorber and paraffin composites were measured, as shown in Fig. 7. As depicted in Fig. 6(a and b), the $\varepsilon^{\prime}$ and $\varepsilon^{\prime \prime}$ values of the as-prepared samples all decrease distinctly with the increase in the applied frequency except for PC-18-650; this phenomenon is called the frequency dispersion behaviour, which is beneficial to impedance matching. ${ }^{50-52}$ In addition, it can be clearly seen that the walnut shells calcined at $600{ }^{\circ} \mathrm{C}$ directly (C-600) exhibit low $\varepsilon^{\prime}$ values (ranging from 5.2 to 4.1). Interestingly, the walnut shells activated by $\mathrm{ZnCl}_{2}$ at $600{ }^{\circ} \mathrm{C}$ present distinctly higher $\varepsilon^{\prime}$ values than C-600 and the $\varepsilon^{\prime}$ values of the as-prepared samples increase with the increase in the $\mathrm{ZnCl}_{2}$ concentration. This phenomenon can be explained through the microstructure analysis. As depicted in the analysis of $\mathrm{N}_{2}$ adsorptiondesorption isotherms, the samples activated by $\mathrm{ZnCl}_{2}$ have obviously more micropores than C-600. The effective permittivity of a porous material can be obtained through the Maxwell-Garnett equation: ${ }^{53-55}$

$$
\varepsilon_{\mathrm{eff}}^{\mathrm{MG}}=\left[\frac{\left(\varepsilon_{2}+2 \varepsilon_{1}\right)+2 f_{\mathrm{r}}\left(\varepsilon_{2}-\varepsilon_{1}\right)}{\left(\varepsilon_{2}+2 \varepsilon_{1}\right)-f_{\mathrm{r}}\left(\varepsilon_{2}-\varepsilon_{1}\right)}\right] \varepsilon_{1}
$$

Here, $\varepsilon_{1}$ and $\varepsilon_{2}$ correspond to the permittivities of the host and guest, and $f_{\mathrm{r}}$ stands for the volume fraction of the guest in the effective medium. Theoretically, the porous structure can reduce the permittivity of the material because the permittivity of air (the guest) is far lower than that of the material itself (the host). Nevertheless, when the pores are micropores $(<2 \mathrm{~nm})$, they can enhance the permittivity of the material because some
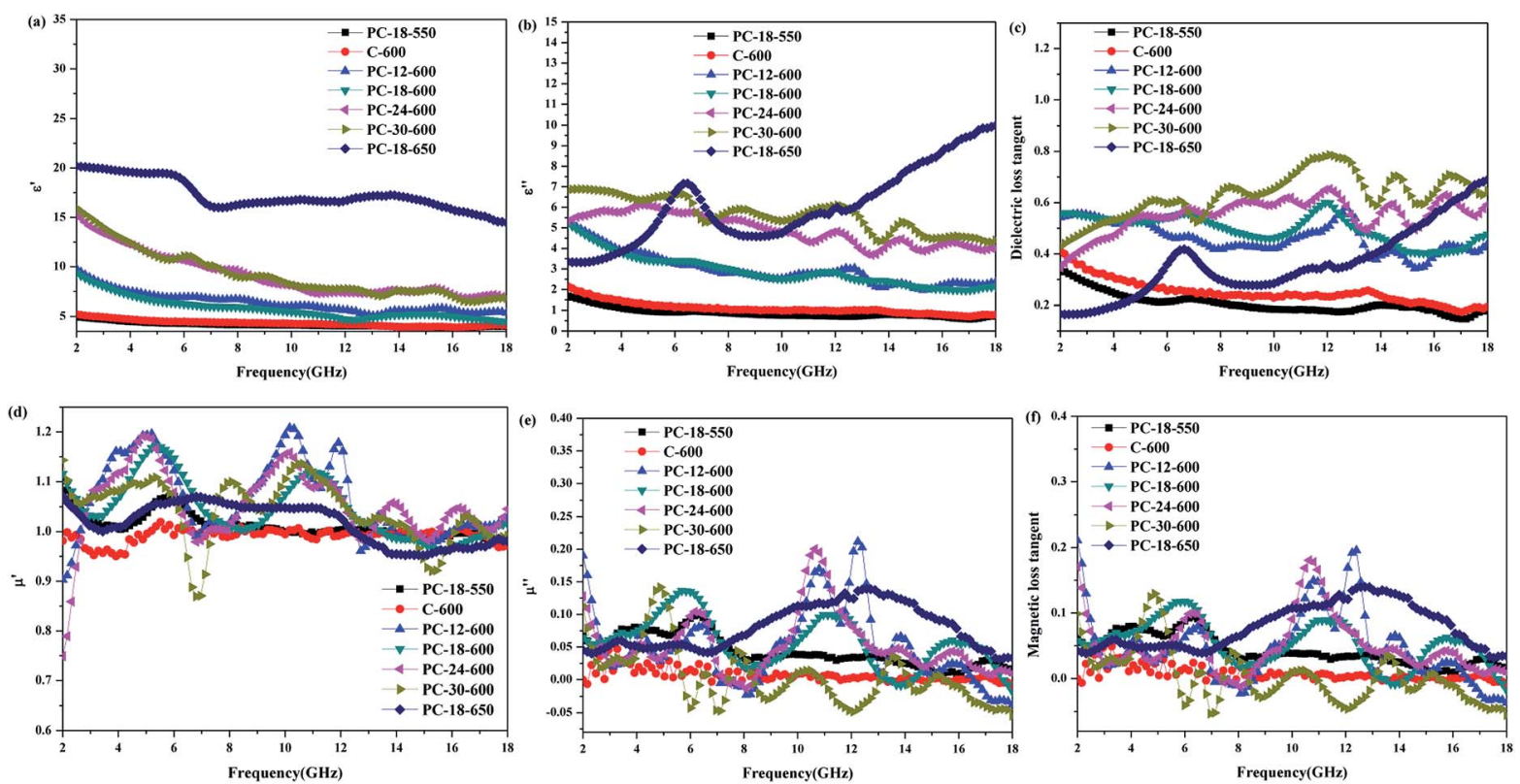

Fig. 7 Frequency dependence of electromagnetic parameters of the composites: (a) the real part $\left(\varepsilon^{\prime}\right)$ and $(b)$ imaginary part $\left(\varepsilon^{\prime \prime}\right)$ of complex permittivity, (c) the dielectric loss tangent, (d) the real part $\left(\mu^{\prime}\right)$ and (e) imaginary part $\left(\mu^{\prime \prime}\right)$ of complex permeability, (f) the magnetic loss tangent. 
electrons accumulate in the walls of the pores to form interfacial polarization in the presence of electromagnetic waves due to differences in the conductivities of the material itself and air inside the material. ${ }^{56,57}$ Furthermore, the $\varepsilon^{\prime}$ values (Fig. 7(a)) have high positive correlation with the calculated $I_{\mathrm{D}} / I_{\mathrm{G}}$ values (Fig. 4) of the as-prepared samples. As mentioned above, the $I_{\mathrm{D}} /$ $I_{\mathrm{G}}$ values can effectively reflect the graphitization degree and the defect concentration of carbonaceous materials; the higher $I_{\mathrm{D}} /$ $I_{\mathrm{G}}$ values indicate higher defect concentration in carbonaceous materials. Thus, it can be speculated that the defects in carbonaceous materials make a great contribution to the enhancement in $\varepsilon^{\prime}$ values. When the electromagnetic wave propagates into the interior of the material, the defects can become polarization centers, which results in the increase in the $\varepsilon^{\prime}$ values. ${ }^{39,40}$

As depicted in Fig. 7(b and c), C-600 has low $\varepsilon^{\prime \prime}$ values (ranging from 2.15 to 0.79 ) and dielectric loss tangent (ranging from 0.41 to 0.19 ). This indicates that C-600 has poor dielectric loss capacity, which decreases the microwave absorption performance. Interestingly, the samples activated by $\mathrm{ZnCl}_{2}$ have distinctly higher $\varepsilon^{\prime \prime}$ values and dielectric loss tangent due to the interfacial polarization and defects inside the material. ${ }^{58,59}$ In addition, it can be seen that the samples activated at higher temperatures have higher $\varepsilon^{\prime \prime}$ values. However, it is worth noting that although PC-18-650 has higher $\varepsilon^{\prime}$ and $\varepsilon^{\prime \prime}$ values than the other as-prepared samples, its dielectric loss tangent is relatively low; this indicates that it has good storage capacity of electromagnetic waves but not good dielectric loss capacity, which is unfavourable for its microwave absorption performance. ${ }^{60}$

As indicated in Fig. 7(d-f), the $\mu^{\prime}$ and $\mu^{\prime \prime}$ values of the asprepared samples are around 1 and 0 , respectively. The low $\mu^{\prime}$ and $\mu^{\prime \prime}$ values of the as-prepared samples indicate that the samples have poor magnetic loss capacities because the samples are diamagnetic. Therefore, if the $\varepsilon^{\prime}$ and $\varepsilon^{\prime \prime}$ values of the as-prepared samples are very high, they are not beneficial to the impedance matching of the samples, which will make a majority of electromagnetic waves reflect on the outer surface of the samples directly. ${ }^{61}$

According to eqn (1) and (2), the microwave absorption performances of the as-prepared samples are simulated, as depicted in Fig. 8. It can be seen that the C-600 samples with various thicknesses present poor microwave absorption performances and they do not meet the requirements of effective absorption (the reflection loss $\leq-10 \mathrm{~dB}, 90 \%$ absorption) in the frequency range from 2.0 to $18.0 \mathrm{GHz}$. The poor microwave absorbing performances of C-600 can be attributed to its poor dielectric loss properties. Nevertheless, the microwave absorbing performances of walnut shells activated by $\mathrm{ZnCl}_{2}$ have dramatic improvements due to the enhanced dielectric loss properties. PC-18-600 with an absorber thickness of $2.5 \mathrm{~mm}$ has the minimum reflection loss of $-22.8 \mathrm{~dB}$ at 14.0 $\mathrm{GHz}$ and the effective absorption (the reflection loss $\leq-10 \mathrm{~dB}$ ) bandwidth is $7.2 \mathrm{GHz}$ (ranging from $10.8 \mathrm{GHz}$ to $18.0 \mathrm{GHz}$ ); however, when the absorber thickness is $2.0 \mathrm{~mm}$, its minimum reflection loss is only $-17.1 \mathrm{~dB}$ at $18.0 \mathrm{GHz}$ and the effective absorption bandwidth is only $2.9 \mathrm{GHz}$ (ranging from $15.1 \mathrm{GHz}$ to $18.0 \mathrm{GHz}$ ). Therefore, the absorber thickness has a great impact on the microwave absorption performance. Usually, it is believed that the more the absorber thickness, the better the microwave absorption performance. In fact, if the absorber thickness is considerable, the microwave absorption performance will be worse. For instance, PC-24-600 with an absorber thickness of $2.0 \mathrm{~mm}$ has the minimum reflection loss of -21.0 $\mathrm{dB}$ at $13.5 \mathrm{GHz}$ and the effective absorption bandwidth is 6.0 $\mathrm{GHz}$ (ranging from $11.4 \mathrm{GHz}$ to $17.4 \mathrm{GHz}$ ); however, when the absorber thickness is $2.5 \mathrm{~mm}$, its minimum reflection loss is only $-15.7 \mathrm{~dB}$ at $9.8 \mathrm{GHz}$ and its effective absorption bandwidth is only $4.7 \mathrm{GHz}$ (ranging from $8.7 \mathrm{GHz}$ to $13.4 \mathrm{GHz}$ ). PC-30-600 with an absorber thickness of $2.0 \mathrm{~mm}$ has the minimum reflection loss of $-17.0 \mathrm{~dB}$ at $13.8 \mathrm{GHz}$ and its effective absorption bandwidth is $6.4 \mathrm{GHz}$ (ranging from $11.3 \mathrm{GHz}$ to 17.7 GHz); however, when the absorber thickness is $2.5 \mathrm{~mm}$, its minimum reflection loss is only $-14.8 \mathrm{~dB}$ at $10.0 \mathrm{GHz}$ and its effective absorption bandwidth is only $3.3 \mathrm{GHz}$ (ranging from 8.6 GHz to $11.9 \mathrm{GHz}$ ). In addition, a phenomenon can be found that all the minimum reflection loss peaks of the samples shift to a lower frequency with the increase in the absorber thickness. These phenomena can be elucidated by the $1 / 4$ wavelength equation: ${ }^{62}$

$$
t_{\mathrm{m}}=\frac{n c}{4 f_{\mathrm{m}} \sqrt{\left|\varepsilon_{\mathrm{r}} \mu_{\mathrm{r}}\right|}} \quad(n=1,3,5 \ldots)
$$

Here, $t_{\mathrm{m}}$ and $f_{\mathrm{m}}$ correspond to the matching thickness and frequency at the minimum reflection loss peak; $\varepsilon_{\mathrm{r}}$ and $\mu_{\mathrm{r}}$ stand for the complex permittivity and permeability at $f_{\mathrm{m}}$, respectively, and $c$ is the velocity of light. Hence, on the one hand, more absorber thickness does not indicate better microwave absorption performance and a reasonable absorber thickness depends on the complex permittivity and permeability of the absorber. On the other hand, the matching frequency or minimum reflection loss peaks of the samples can shift to a lower frequency with the increase in the absorber thickness. As indicated in Fig. 8, it can also be seen that when the absorber thickness is $2.0 \mathrm{~mm}$, PC-24-600 has the minimum reflection loss of $-21.0 \mathrm{~dB}$ at $13.5 \mathrm{GHz}$ and the effective absorption bandwidth is $6.0 \mathrm{GHz}$ (ranging from $11.4 \mathrm{GHz}$ to $17.4 \mathrm{GHz}$ ), while the minimum reflection loss of PC-18-600 is only -17.1 $\mathrm{dB}$ at $18.0 \mathrm{GHz}$ and the effective absorption bandwidth is only 2.9 $\mathrm{GHz}$ (ranging from $15.1 \mathrm{GHz}$ to $18.0 \mathrm{GHz}$ ). When the absorber thickness is $2.5 \mathrm{~mm}$, PC-24-600 has the minimum reflection loss of only $-15.7 \mathrm{~dB}$ at $9.8 \mathrm{GHz}$ and the effective absorption bandwidth is only $4.7 \mathrm{GHz}$ (ranging from $8.7 \mathrm{GHz}$ to 13.4 GHz), while PC-18-600 has the minimum reflection loss of $-22.8 \mathrm{~dB}$ at $14.0 \mathrm{GHz}$ and the effective absorption bandwidth is $7.2 \mathrm{GHz}$ (ranging from $10.8 \mathrm{GHz}$ to $18.0 \mathrm{GHz}$ ). The PC-18-600 and PC-24-600 samples both have excellent absorbing performances. We further processed the data to pick out the best between them. As shown in Fig. 9, $\Delta S\left(\Delta S=\int \mathrm{RLd} f \mid \mathrm{RL} \leq-10\right.$ $\mathrm{dB}$ ) is defined as the area of effective absorbing (RL $\leq-10 \mathrm{~dB}$ ). For PC-18-600 and PC-24-600, the $\Delta S$ values are 36.08 and 22.15 , respectively. Then, we define $R_{\mathrm{E}}\left(R_{\mathrm{E}}=\Delta S / d\right)$ as the electromagnetic absorption efficiency. ${ }^{63,64}$ For PC-18-600 and PC24-600, the $R_{\mathrm{E}}$ values are 14.43 and 11.07 , respectively. Thus, it 

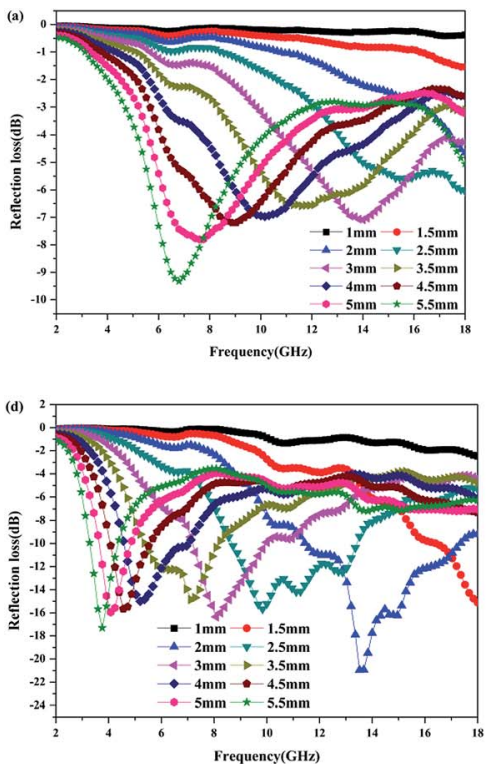
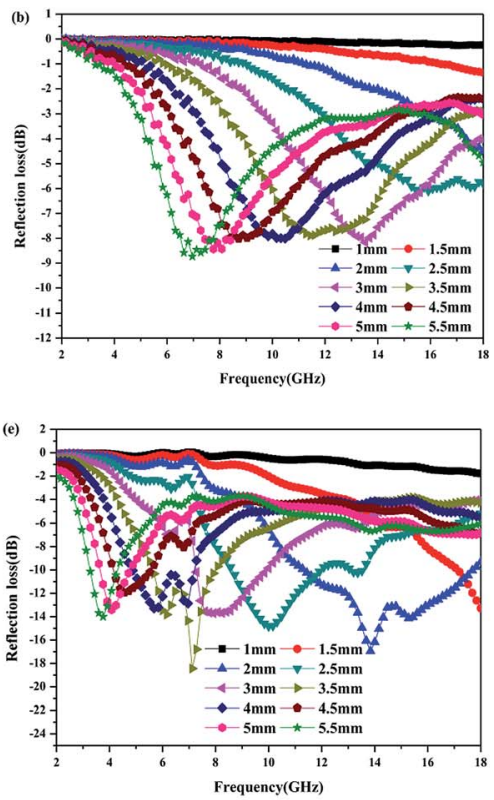
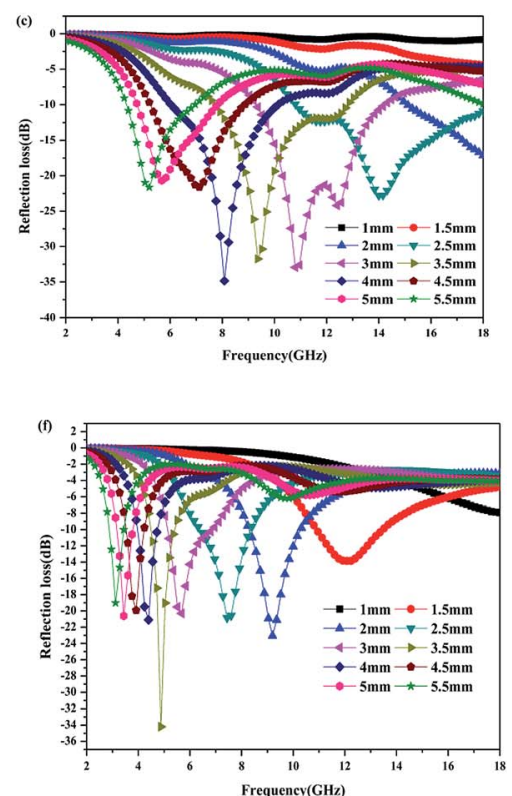

Fig. 8 Reflection loss curves of PC-18-550 (a), C-600 (b), PC-18-600 (c), PC-24-600 (d), PC-30-600 (e) and PC-18-650 (f) at various absorber thicknesses.
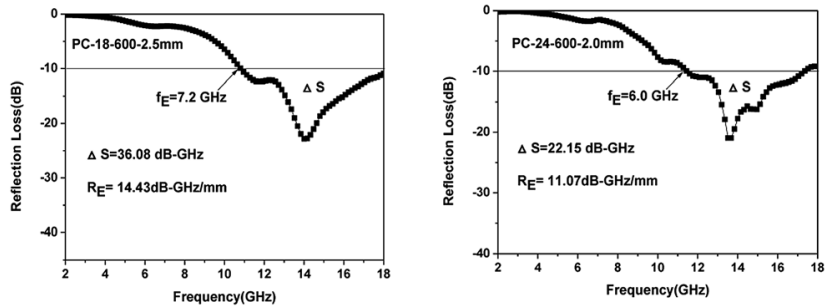

Fig. 9 Reflection loss of PC-18-600 - $2.5 \mathrm{~mm}$ and PC-24-600 - 2.0 $\mathrm{mm}$.

can be deduced that the sample showing the best electromagnetic wave absorption properties is PC-18-600.

Furthermore, we discussed the Cole-Cole semicircles and detailed the interfacial polarization relaxation effect of walnut shell-derived nano-porous carbon. We know that the Debye dipolar relaxation is expressed as follows: $\left(\varepsilon^{\prime}-\varepsilon_{\infty}\right)^{2}+\left(\varepsilon^{\prime \prime}\right)^{2}=\left(\varepsilon_{\mathrm{s}}-\varepsilon_{\infty}\right)^{2}$; here, $\varepsilon_{\mathrm{S}}$ and $\varepsilon_{\infty}$ are the stationary dielectric constant and the optical dielectric constant, respectively. Thus, the plot of $\varepsilon^{\prime}$ versus $\varepsilon^{\prime \prime}$ is a single semicircle, which can be defined as the Cole-Cole semicircle. ${ }^{65}$ In Fig. 10, we can easily see that PC-18-600 presents a clear segment of three semicircles, suggesting the existence of ternary dielectric relaxation processes, and each semicircle corresponds to a Debye dipolar relaxation.

Representative carbon-based materials with excellent microwave absorption performances in recent years are listed in Table 2. Rice husk-based hierarchically porous carbon (RHPC)/ Fe and RHPC/Co were prepared by a pre-modification method and a post-modification method; the minimum reflection loss of $\mathrm{RHPC} / \mathrm{Fe}$ was $-21.8 \mathrm{~dB}$ at $14.0 \mathrm{GHz}$ and its effective absorption bandwidth was $5.6 \mathrm{GHz}$ (ranging from $12.4 \mathrm{GHz}$ to $18.0 \mathrm{GHz}$ ) when the absorber thickness was only $1.4 \mathrm{~mm}$; the

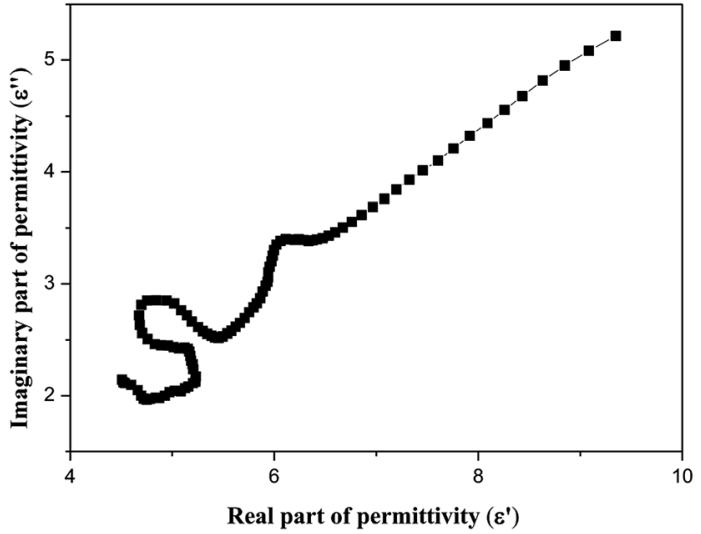

Fig. 10 Cole-Cole semicircles for PC-18-600.

minimum reflection loss of RHPC/Co was $-40.1 \mathrm{~dB}$ at $10.7 \mathrm{GHz}$ and its effective absorption bandwidth was $2.7 \mathrm{GHz}$ (ranging from $9.3 \mathrm{GHz}$ to $12.0 \mathrm{GHz}$ ) when the absorber thickness was only $1.8 \mathrm{~mm} .^{28}$ Wood-based porous biomass carbon was prepared by the pyrolysis of natural wood. The natural wood annealed at $680^{\circ} \mathrm{C}$ has the minimum reflection loss of $-68.3 \mathrm{~dB}$ at $11.0 \mathrm{GHz}$ and its effective absorption bandwidth is $6.13 \mathrm{GHz}$ (ranging from $8.20 \mathrm{GHz}$ to $14.33 \mathrm{GHz}$ ) when the absorber thickness is $4.28 \mathrm{~mm}$; the natural wood annealed at $690{ }^{\circ} \mathrm{C}$ has the minimum reflection loss of $-16.3 \mathrm{~dB}$ at $11.5 \mathrm{GHz}$ and its effective absorption bandwidth is $7.63 \mathrm{GHz}$ (ranging from 9.83 $\mathrm{GHz}$ to $17.46 \mathrm{GHz}$ ) when the absorber thickness is $3.73 \mathrm{~mm} .{ }^{21} \mathrm{~A}$ Co@crystalline carbon@carbon aerogel composite was prepared by using alginate aerogels as the precursors; it exhibited the minimum reflection loss of $-43 \mathrm{~dB}$ at $17.9 \mathrm{GHz}$ and its effective absorption bandwidth was $2.6 \mathrm{GHz}$ (ranging 
Table 2 The representative carbon-based materials with excellent microwave absorption performances in recent years

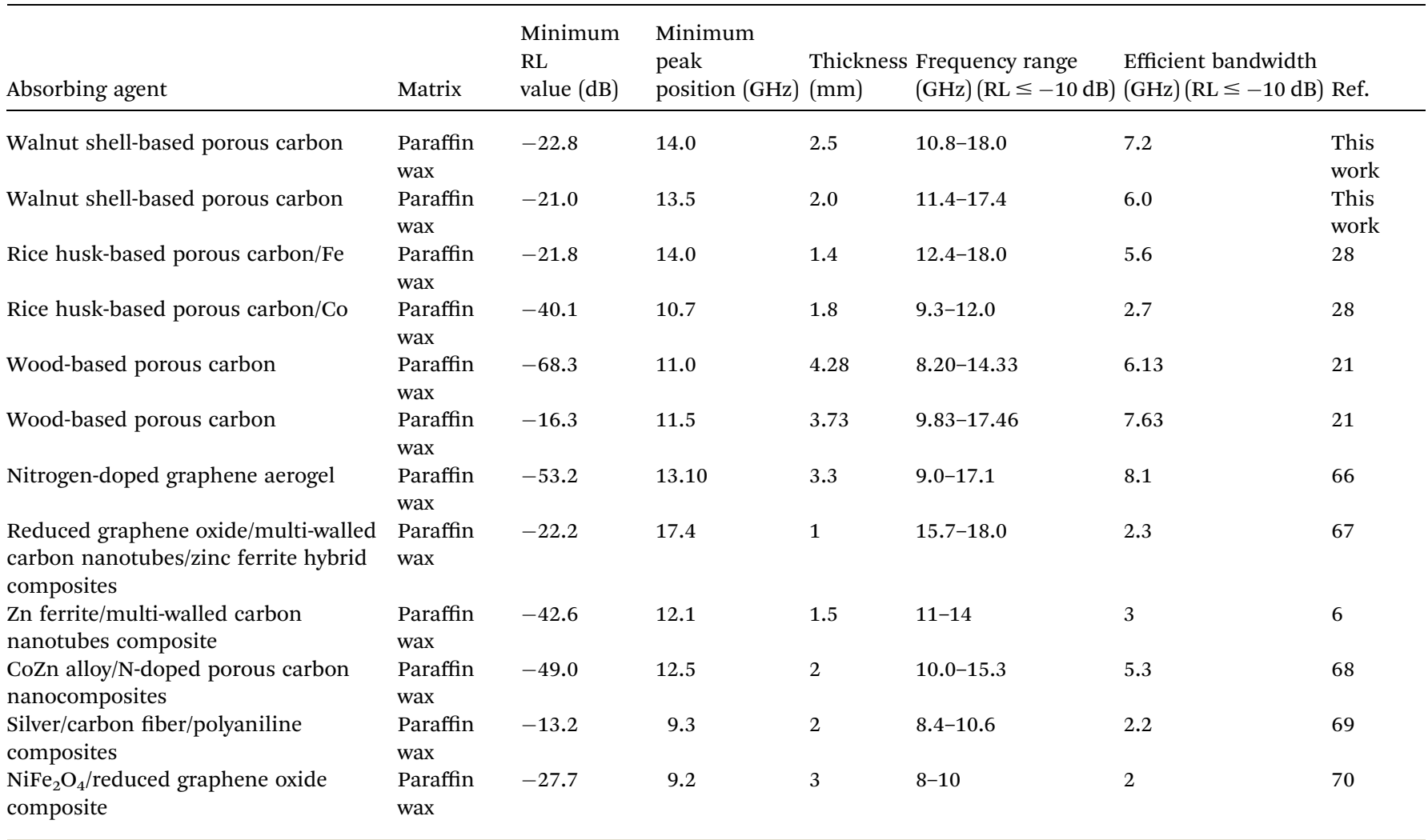

from $15.4 \mathrm{GHz}$ to $18.0 \mathrm{GHz}$ ) with the absorber thickness of 1.5 $\mathrm{mm}$. In this work, the minimum reflection loss of PC-18-600 is $-22.8 \mathrm{~dB}$ at $14.0 \mathrm{GHz}$ and its effective absorption bandwidth can reach $7.2 \mathrm{GHz}$ (ranging from $10.8 \mathrm{GHz}$ to $18.0 \mathrm{GHz}$ ) with an absorber thickness of $2.5 \mathrm{~mm}$; the minimum reflection loss of PC-24-600 is $-21.0 \mathrm{~dB}$ at $13.5 \mathrm{GHz}$ and its effective absorption bandwidth can reach $6.0 \mathrm{GHz}$ (ranging from $11.4 \mathrm{GHz}$ to 17.4 $\mathrm{GHz}$ ) with an absorber thickness of only $2.0 \mathrm{~mm}$. Compared with other carbonaceous microwave absorbers, the as-prepared samples in this work have wide effective absorption bandwidths with low absorber thicknesses, which improves their practicability.

In the end, probable microwave absorption principles of walnut shell-derived nano-porous carbon need to be generalized. On the one hand, the material structure has a great influence on the microwave absorption performance of the material. Porous structures are conducive to microwave absorption because microwaves will make multiple reflections and scatter in the porous structure and the propagation path is prolonged, which strengthens the microwave attenuation capacity of the material. On the other hand, the microwave absorption performance of the material is determined by its electromagnetic parameters. Walnut shell-derived nano-porous carbon is diamagnetic; thus, the dielectric loss capacity of the material plays the leading role in affecting the microwave absorption performance of the material. Two factors make great contributions to the improvement in the dielectric loss capacity of the material. On the one hand, the defects in the walnut shellderived nano-porous carbon can become polarized centers when the microwave transmits to the sample, which enhances the dielectric loss capacity of the material. On the other hand, some electrons accumulate in the walls of the pores to cause interfacial polarization when the microwave transmits to the sample, which can also enhance the dielectric loss capacity of the material. However, the walnut shell-derived nano-porous carbon is diamagnetic and it has low complex permeability values; thus, if the dielectric loss capacity of the material is very strong, it will deteriorate the impedance matching of the material, which indicates that majority of microwaves will reflect on the outside surface of the material directly rather than propagate into the interior of the material.

\section{Conclusion}

In conclusion, a walnut shell-derived nano-porous carbon was successfully prepared via a facile method with the assistance of $\mathrm{ZnCl}_{2}$. Walnut shells calcined at $600{ }^{\circ} \mathrm{C}$ directly (C-600) revealed poor microwave absorption performance because of the poor dielectric loss capacity. Nevertheless, when the walnut shells were activated by $\mathrm{ZnCl}_{2}$, the specific surface areas, dielectric loss capacities and microwave absorption performances of the samples improved significantly. Two factors can account for the improvement in the microwave absorption performances of the samples activated by $\mathrm{ZnCl}_{2}$. On the one hand, the specific surface area of the sample increased distinctly via $\mathrm{ZnCl}_{2}$ activation and due to the porous structures, the microwaves exhibited multiple reflections and scattering, which can strengthen the microwave absorption performance. On the 
other hand, the dielectric loss capacity of the sample was enhanced via $\mathrm{ZnCl}_{2}$ activation, which was beneficial to microwave attenuation. The reinforcement of the dielectric loss capacity was attributed to the interfacial polarization in the walls of the pores and the increased defects, which can become polarized centers in the sample when the microwave transmits to the sample. In this work, for PC-18-600, the minimum reflection loss could reach $-22.8 \mathrm{~dB}$ at $14.0 \mathrm{GHz}$ and the effective absorption (the reflection loss $\leq-10 \mathrm{~dB}$ ) bandwidth could reach 7.2 $\mathrm{GHz}$ (ranging from $10.8 \mathrm{GHz}$ to $18.0 \mathrm{GHz}$ ) when the absorber thickness was $2.5 \mathrm{~mm}$. Hence, the as-prepared samples can have low densities, strong microwave absorption performances and wide effective absorption bandwidths with low absorber thicknesses, due to which they have a great potential as lightweight and efficient microwave absorbers. Furthermore, the $\mathrm{ZnCl}_{2}$ activation method in this work can be extended as a universal method to improve the dielectric loss capacity and the microwave absorption performance of carbonaceous materials.

\section{Conflicts of interest}

There are no conflicts to declare.

\section{Acknowledgements}

The authors acknowledge the generous financial support from Priority Academic Program Development of Jiangsu Higher Education Institutions (PAPD), National Natural Science Foundation of China (51202111), the Top-notch Academic Programs Project of Jiangsu Higher Education Institutions (TAPP, PPZY2015B128) and National Pre-research Foundation of China (61402080102).

\section{Notes and references}

1 J. Guo, H. X. Song, H. Liu, C. J. Luo, Y. R. Ren, T. Ding, M. A. Khan, D. P. Young, X. Y. Liu, X. Zhang, J. Kong and Z. H. Guo, Polypyrrole-interface-functionalized nanomagnetite epoxy nanocomposites as electromagnetic wave absorbers with enhanced flame retardancy, J. Mater. Chem. C, 2017, 5, 5334-5344.

2 J. L. Liu, P. Zhang, X. K. Zhang, Q. Q. Xie, D. J. Pan, J. Zhang and M. Zhang, Synthesis and microwave absorbing properties of La-doped Sr-hexaferrite nanopowders via solgel auto-combustion method, Rare Met., 2017, 36, 704-710.

3 K. Wang, G. P. Wan, G. L. Wang, Z. Y. He, S. H. Shi, L. H. Wu and G. Z. Wang, The construction of carbon-coated $\mathrm{Fe}_{3} \mathrm{O}_{4}$ yolk-shell nanocomposites based on volume shrinkage from the release of oxygen anions for wide-band electromagnetic wave absorption, J. Colloid Interface Sci., 2018, 511, 307-317.

4 W. Liu, Q. W. Shao, G. B. Ji, X. H. Liang, Y. Cheng, B. Quan and Y. W. Du, Metal-organic-frameworks derived porous carbon-wrapped Ni composites with optimized impedance matching as excellent lightweight electromagnetic wave absorber, Chem. Eng. J., 2017, 313, 734-744.

5 X. X. Wang, T. Ma, J. C. Shu and M. S. Cao, Confinedly tailoring $\mathrm{Fe}_{3} \mathrm{O}_{4}$ clusters-NG to tune electromagnetic parameters and microwave absorption with broadened bandwidth, Chem. Eng. J., 2018, 332, 321-330.

6 Z. F. Liu, H. L. Xing, Y. Liu, H. Wang, H. X. Jia and X. L. Ji, Hydrothermally synthesized $\mathrm{Zn}$ ferrite/multi-walled carbon nanotubes composite with enhanced electromagnetic-wave absorption performance, J. Alloys Compd., 2018, 731, 745752.

7 X. G. Huang, J. Zhang, W. Wang, T. Y. Sang, B. Song, H. L. Zhu, W. F. Rao and C. P. Wong, Effect of $\mathrm{pH}$ value on electromagnetic loss properties of Co-Zn ferrite prepared via coprecipitation method, J. Magn. Magn. Mater., 2016, 405, 36-41.

8 X. G. Huang, J. Zhang, Z. H. Liu, T. Y. Sang, B. Song, H. L. Zhu and C. P. Wong, Facile preparation and microwave absorption properties of porous hollow $\mathrm{BaFe}_{12} \mathrm{O}_{19} / \mathrm{CoFe}_{2} \mathrm{O}_{4}$ composite microrods, J. Alloys Compd., 2015, 648, 10721075.

9 T. Shang, Q. S. Lu, L. M. Chao, Y. L. Qin, Y. H. Yun and G. H. Yun, Effects of ordered mesoporous structure and Ladoping on the microwave absorbing properties of $\mathrm{CoFe}_{2} \mathrm{O}_{4}$, Appl. Surf. Sci., 2018, 434, 234-242.

10 J. Liu, M. S. Cao, Q. Luo, H. L. Shi, W. Z. Wang and J. Yuan, Electromagnetic property and tunable microwave absorption of 3D nets from nickel chains at elevated temperature, ACS Appl. Mater. Interfaces, 2016, 8, 2261522622.

11 Q. R. Jiang, H. L. Li, Z. M. Cao, H. Li, Q. X. Wang, Z. Y. Jiang, Q. Kuang and Z. X. Xie, Synthesis and enhanced electromagnetic wave absorption performance of amorphous $\mathrm{Co}_{\mathrm{x}} \mathrm{Fe}_{10-\mathrm{x}}$ alloys, J. Alloys Compd., 2017, 726, 1255-1261.

12 Y. Wang, Y. C. Du, P. Xu, R. Qiang and X. J. Han, Recent advances in conjugated polymer-based microwave absorbing materials, Polymers, 2017, 9, 29.

13 J. L. Xu, X. S. Qi, C. Z. Luo, J. Qiao, R. Xie, Y. Sun, W. Zhong, Q. Fu and C. X. Pan, Synthesis and enhanced microwave absorption properties: a strongly hydrogenated $\mathrm{TiO}_{2}$ nanomaterial, Nanotechnology, 2017, 28, 425701.

14 S. Dong, X. H. Zhang, D. Y. Zhang, B. Q. Sun, L. W. Yan and X. G. Luo, Strong effect of atmosphere on the microstructure and microwave absorption properties of porous $\mathrm{SiC}$ ceramics, J. Eur. Ceram. Soc., 2018, 38, 29-39.

15 H. L. Xu, X. W. Yin, M. Zhu, M. K. Han, Z. X. Hou, X. L. Li, L. T. Zhang and L. F. Cheng, Carbon hollow microspheres with a designable mesoporous shell for high-performance electromagnetic wave absorption, ACS Appl. Mater. Interfaces, 2017, 9, 6332-6341.

16 L. J. Yu, Y. F. Zhu and Y. Q. Fu, Waxberry-like carbon@polyaniline microspheres with high-performance microwave absorption, Appl. Surf. Sci., 2018, 427, 451-457.

17 B. Zhao, B. Fan, Y. Xu, et al., Preparation of Honeycomb $\mathrm{SnO} 2$ Foams and Configuration-Dependent Microwave Absorption Features, ACS Appl. Mater. Interfaces, 2016, 7(47), 26217-26225.

18 P. Y. Liu, L. M. Wang, B. Cao, L. C. Li, K. L. Zhang, X. M. Bian and Z. L. Hou, Designing high-performance electromagnetic wave absorption materials based on polymeric graphene- 
based dielectric composites: from fabrication technology to periodic pattern design, J. Mater. Chem. C, 2017, 5, 67456754.

19 T. Zhang, B. Xiao, P. Y. Zhou, L. Xia, G. W. Wen and H. B. Zhang, Porous-carbon-nanotube decorated carbon nanofibers with effective microwave absorption properties, Nanotechnology, 2017, 28, 355708.

20 B. Zhao, J. Liu, X. Guo, et al., Hierarchical porous Ni@boehmite/nickel aluminum oxide flakes with enhanced microwave absorption ability, Phys. Chem. Chem. Phys., 2017, 19(13), 9128.

21 J. B. Xi, E. Z. Zhou, Y. J. Liu, W. W. Gao, J. Ying, Z. C. Chen and C. Gao, Wood-based straightway channel structure for high performance microwave absorption, Carbon, 2017, 124, 492-498.

22 L. J. Xie, G. H. Sun, F. Y. Su, X. Q. Guo, Q. Q. Kong, X. M. Li, X. H. Huang, L. Wan, W. Song, K. X. Li, C. X. Lv and C. M. Chen, J. Mater. Chem. A, 2016, 4, 1637-1646.

23 X. Tian, S. Zhu, J. Peng, Y. T. Zuo, G. Wang, X. H. Guo, N. Q. Zhao, Y. Q. Ma and L. Ma, Electrochim. Acta, 2017, 241, 170-178.

24 X. Tian, H. G. Ma, Z. Li, S. C. Yan, L. Ma, F. Yu, G. Wang, X. H. Guo, Y. Q. Ma and C. P. Wong, Flute type micropores activated carbon from cotton stalk for high performance supercapacitors, J. Power Sources, 2017, 359, 88-96.

25 Y. C. Zhang, Y. You, S. Xin, Y. X. Yin, J. Zhang, P. Wang, X. S. Zheng, F. F. Cao and Y. G. Guo, Rice husk-derived hierarchical silicon/nitrogen-doped carbon/carbon nanotube spheres as low-cost and high-capacity anodes for lithium-ion batteries, Nano Energy, 2016, 25, 120-127.

26 M. Nowrouzi, H. Younesi and N. Bahramifar, High efficient carbon dioxide capture onto as-synthesized activated carbon by chemical activation of Persian Ironwood biomass and the economic pre-feasibility study for scaleup, J. Cleaner Prod., 2017, 168, 499-509.

27 P. Benjwal, R. Sharma and K. K. Kar, Effects of surface microstructure and chemical state of featherfiber-derived multidoped carbon fibers on the adsorption of organic water pollutants, Mater. Des., 2016, 110, 762-774.

28 J. Y. Fang, Y. S. Shang, Z. Chen, W. Wei, Y. Hu, X. G. Yue and Z. H. Jiang, Rice husk-based hierarchically porous carbon and magnetic particles composites for highly efficient electromagnetic wave attenuation, J. Mater. Chem. C, 2017, 5, 4695-4705.

29 N. N. Wang, F. Wu, A. M. Xie, X. Q. Dai, M. X. Sun, Y. Y. Qiu, Y. Wang, X. L. Lv and M. Y. Wang, One-pot synthesis of biomass-derived carbonaceous spheres for excellent microwave absorption at the Ku band, RSC Adv., 2015, 5, 40531-40535.

$30 \mathrm{~J}$. C. Wang and S. Kaskel, $\mathrm{KOH}$ activation of carbon-based materials for energy storage, J. Mater. Chem., 2012, 22, 23710-23725.

31 C. C. Dai, J. F. Wan, W. D. Geng, S. J. Song, F. W. Ma and J. Q. Shao, KOH direct treatment of kombucha and in situ activation to prepare hierarchical porous carbon for highperformance supercapacitor electrodes, J. Solid State Electrochem., 2017, 21, 2929-2938.
32 P. Cheng, S. Y. Gao, P. Y. Zang, X. F. Yang, Y. L. Bai, H. Xu, Z. H. Liu and Z. B. Lei, Hierarchically porous carbon by activation of shiitake mushroom for capacitive energy storage, Carbon, 2015, 93, 315-324.

33 X. N. Ye, Q. Lu, X. Wang, H. Q. Guo, M. S. Cui, C. Q. Dong and Y. P. Yang, Catalytic fast pyrolysis of cellulose and biomass to selectively produce levoglucosenone using activated carbon catalyst, ACS Sustainable Chem. Eng., 2017, 5, 10815-10825.

34 M. Sevilla and A. B. Fuertes, Sustainable porous carbons with a superior performance for $\mathrm{CO}_{2}$ capture, Energy Environ. Sci., 2011, 4, 1765-1771.

35 H. Sun, R. C. Che, X. You, Y. S. Jiang, Z. B. Yang, J. Deng, L. B. Qiu and H. S. Peng, Cross-stacking aligned carbonnanotube films to tune microwave absorption frequencies and increase absorption intensities, Adv. Mater., 2014, 26, 8120-8125.

36 P. Singh, V. K. Babbar, A. Razdan, R. K. Puri and T. C. Goel, Complex permittivity, permeability, and X-band microwave absorption of CaCoTi ferrite composites, J. Appl. Phys., 2000, 87, 4362-4366.

37 G. Ma, Q. Yang, K. Sun, et al., Nitrogen-doped porous carbon derived from biomass waste for high-performance supercapacitor, Bioresour. Technol., 2015, 197, 137-142.

38 H. L. Zhu, F. Shen, W. Luo, S. Z. Zhu, M. H. Zhao, B. Natarajan, J. Q. Dai, L. H. Zhou, X. L. Ji, R. S. Yassar, T. $\mathrm{Li}$ and L. B. Hu, Low temperature carbonization of cellulose nanocrystals for high performance carbon anode of sodium-ion batteries, Nano Energy, 2017, 33, 37-44.

39 P. C. P. Watts, W. K. Hsu, A. Barnes and B. Chambers, High permittivity from defective multiwalled carbon nanotubes in the X-Band, Adv. Mater., 2003, 15, 600-603.

40 B. Wen, M. S. Cao, M. M. Lu, W. Q. Cao, H. L. Shi, J. Liu, X. X. Wang, H. B. Jin, X. Y. Fang, W. Z. Wang and J. Yuan, Reduced graphene oxides: light-weight and high-efficiency electromagnetic interference shielding at elevated temperatures, Adv. Mater., 2014, 26, 3484-3489.

41 T. Z. Yang, T. Qian, M. F. Wang, X. W. Shen, N. Xu, Z. Z. Sun and C. L. Yan, A sustainable route from biomass byproduct okara to high content nitrogen-doped carbon sheets for efficient sodium ion batteries, Adv. Mater., 2016, 28, 539545.

42 M. Sevilla and A. B. Fuertes, Direct synthesis of highly porous interconnected carbon nanosheets and their application as high-performance supercapacitors, ACS Nano, 2014, 8, 5069-5078.

43 A. Sadezky, H. Muckenhuber, H. Grothe, R. Niessner and U. Pöschl, Raman microspectroscopy of soot and related carbonaceous materials: spectral analysis and structural information, Carbon, 2005, 43, 1731-1742.

44 B. Song, L. Y. Li, Z. Y. Lin, Z. K. Wu, K. S. Moon and C. P. Wong, Water-dispersible graphene/polyaniline composites for flexible micro-supercapacitors with high energy densities, Nano Energy, 2015, 16, 470-478.

45 Y. Zhang, Y. Huang, H. H. Chen, Z. Y. Huang, Y. Yang, P. S. Xiao, Y. Zhou and Y. S. Chen, Composition and structure control of ultralight graphene foam for high- 
performance microwave absorption, Carbon, 2016, 105, 438447.

46 S. A. Wei, X. X. Wang, B. Q. Zhang, M. X. Yu, Y. W. Zheng, Y. Wang and J. Q. Liu, Preparation of hierarchical coreshell C@NiCo $\mathrm{O}_{4} @ \mathrm{Fe}_{3} \mathrm{O}_{4}$ composites for enhanced microwave absorption performance, Chem. Eng. J., 2017, 314, 477-487.

47 Y. W. Zheng, X. X. Wang, S. Wei, B. Q. Zhang, M. X. Yu, W. Zhao and J. Q. Liu, Fabrication of porous graphene$\mathrm{Fe}_{3} \mathrm{O}_{4}$ hybrid composites with outstanding microwave absorption performance, Composites, Part A, 2017, 95, 237247.

48 Y. C. Du, W. W. Liu, R. Qiang, Y. Wang, X. J. Han, J. Ma and $\mathrm{P}$. $\mathrm{Xu}$, Shell thickness-dependent microwave absorption of core-shell $\mathrm{Fe}_{3} \mathrm{O}_{4} @ \mathrm{C}$ composites, ACS Appl. Mater. Interfaces, 2014, 6, 12997-13006.

49 Q. M. Su, J. Li, G. Zhong, G. H. Du and B. S. Xu, In situ synthesis of iron/nickel sulfide nanostructures-filled carbon nanotubes and their electromagnetic and microwave-absorbing properties, J. Phys. Chem. C, 2011, 115, 1838-1842.

50 Y. X. Huang, Y. Wang, Z. M. Li, Z. Yang, C. H. Shen and C. C. He, Effect of pore morphology on the dielectric properties of porous carbons for microwave absorption applications, J. Phys. Chem. C, 2014, 118, 26027-26032.

51 G. Li, T. S. Xie, S. L. Yang, J. H. Jin and J. M. Jiang, Microwave absorption enhancement of porous carbon fibers compared with carbon nanofibers, J. Phys. Chem. C, 2012, 116, 91969201.

52 N. J. Tang, W. Zhong, C. T. Au, Y. Yang, M. G. Han, K. J. Lin and Y. W. Du, Synthesis, microwave electromagnetic, and microwave absorption properties of twin carbon nanocoils, J. Phys. Chem. C, 2008, 112, 19316-19323.

53 Y. C. Du, T. Liu, B. Yu, H. B. Gao, P. Xu, J. Y. Wang, X. H. Wang and X. J. Han, The electromagnetic properties and microwave absorption of mesoporous carbon, Mater. Chem. Phys., 2012, 135, 884-891.

54 O. Levy and D. Stroud, Maxwell Garnett theory for mixtures of anisotropic inclusions: application to conducting polymers, Phys. Rev. B, 1997, 56, 8035-8046.

55 Q. L. Liu, D. Zhang and T. X. Fan, Electromagnetic wave absorption properties of porous carbon/Co nanocomposites, Appl. Phys. Lett., 2008, 93, 013110.

56 X. Qiu, L. X. Wang, H. L. Zhu, Y. K. Guan and Q. T. Zhang, Lightweight and efficient microwave absorbing materials based on walnut shell-derived nano-porous carbon, Nanoscale, 2017, 9, 7408-7418.

57 X. F. Zhang, X. L. Dong, H. Huang, D. K. Wang, B. Lv and J. P. Lei, High permittivity from defective carbon-coated $\mathrm{Cu}$ nanocapsules, Nanotechnology, 2007, 18, 275701.

58 J. Z. He, X. X. Wang, Y. L. Zhang and M. S. Cao, Small magnetic nanoparticles decorating reduced graphene oxides to tune the electromagnetic attenuation capacity, $J$. Mater. Chem. C, 2016, 4, 7130-7140.

59 M. M. Lu, W. Q. Cao, H. L. Shi, X. Y. Fang, J. Yang, Z. L. Hou, H. B. Jin, W. Z. Wang, J. Yuan and M. S. Cao, Multi-wall carbon nanotubes decorated with $\mathrm{ZnO}$ nanocrystals: mild solution-process synthesis and highly efficient microwave absorption properties at elevated temperature, J. Mater. Chem. A, 2014, 2, 10540-10547.

60 B. Zhao, X. Guo, W. Zhao, et al., Facile synthesis of yolk-shell $\mathrm{Ni@void@SnO} \mathrm{Sn}_{2}\left(\mathrm{Ni}_{3} \mathrm{Sn}_{2}\right)$ ternary composites via galvanic replacement/Kirkendall effect and their enhanced microwave absorption properties, Nano Res., 2017, 10(1), 331-343.

61 Y. Y. Lü, Y. T. Wang, H. L. Li, Y. Lin, Z. Y. Jiang, Z. X. Xie, Q. Kuang and L. S. Zheng, MOF-derived porous $\mathrm{Co} / \mathrm{C}$ nanocomposites with excellent electromagnetic wave absorption properties, ACS Appl. Mater. Interfaces, 2015, 7, 13604-13611.

62 X. M. Zhang, G. B. Ji, W. Liu, B. Quan, X. H. Liang, C. M. Shang, Y. Cheng and Y. W. Du, Thermal conversion of an $\mathrm{Fe}_{3} \mathrm{O}_{4}$ @metal-organic framework: a new method for an efficient $\mathrm{Fe}-\mathrm{Co} /$ nanoporous carbon microwave absorbing material, Nanoscale, 2015, 7, 12932-12942.

63 B. Zhao, X. Guo, W. Zhao, et al., Yolk-Shell Ni@SnO 2 Composites with a Designable Interspace To Improve the Electromagnetic Wave Absorption Properties, ACS Appl. Mater. Interfaces, 2016, 8(42), 28917-28925.

64 J. Deng, S. Li, Y. Zhou, et al., Enhancing the microwave absorption properties of amorphous $\mathrm{CoO}$ nanosheetcoated Co (hexagonal and cubic phases) through interfacial polarizations, J. Colloid Interface Sci., 2018, 509, 406-413.

65 X. L. Dong, X. F. Zhang, H. Huang, et al., Enhanced Microwave Absorption in Ni/Polyaniline Nanocomposites by Dual Dielectric Relaxations, Appl. Phys. Lett., 2008, 92(1), 301.

66 J. Zhou, Y. J. Chen, H. Li, R. Dugnani, Q. Du, H. UrRehman, H. M. Kang and H. Z. Liu, Facile synthesis of threedimensional lightweight nitrogen-doped graphene aerogel with excellent electromagnetic wave absorption properties, J. Mater. Sci., 2018, 53, 4067-4077.

67 R. W. Shu, G. Y. Zhang, J. B. Zhang, X. Wang, M. Wang, Y. Gan, J. J. Shi and J. He, Fabrication of reduced graphene oxide/multi-walled carbon nanotubes/zinc ferrite hybrid composites as high-performance microwave absorbers, $J$. Alloys Compd., 2018, 736, 1-11.

68 W. Feng, Y. M. Wang, J. C. Chen, B. Q. Li, L. X. Guo, J. H. Quyang, D. C. Jia and Y. Zhou, Metal organic framework-derived CoZn alloy/N-doped porous carbon nanocomposites: tunable surface area and electromagnetic wave absorption properties, J. Mater. Chem. C, 2018, 6, 1018.

69 B. Cheng, J. Wang, F. Zhang and S. H. Qi, Preparation of silver/carbon fiber/polyaniline microwave absorption composite and its application in epoxy resin, Polym. Bull., 2018, 75, 381-393.

70 B. Bateer, J. J. Zhang, H. C. Zhang, X. C. Zhang, C. Y. Wang and H. Q. Qi, Easily dispersible $\mathrm{NiFe}_{2} \mathrm{O}_{4} / \mathrm{RGO}$ composite for microwave absorption properties in the X-Band, $J$. Electron. Mater., 2018, 47, 292-298. 